\title{
Estimating the health care burden of prescription opioid abuse in five European countries
}

This article was published in the following Dove Press journal:

ClinicoEconomics and Outcomes Research

15 September 2015

Number of times this article has been viewed

\section{Amie Shei' \\ Matthew Hirst ${ }^{2}$ \\ Noam Y Kirson' \\ Caroline J Enloe' \\ Howard G Birnbaum' \\ William C N Dunlop ${ }^{2}$}

'Analysis Group, Inc., Boston, MA, USA; ${ }^{2}$ Mundipharma International

Limited, Cambridge, UK
Correspondence: William C N Dunlop Mundipharma International Limited, Unit 194, Cambridge Science Park, Milton Road, Cambridge CB4 OAB,

United Kingdom

Tel +44 I 223397678

Email will.dunlop@mundipharma.co.uk
Background: Opioid abuse, including abuse of prescription opioids ("RxOs") and illicit substances like heroin, is a serious public health issue in Europe. Currently, there is limited data on the magnitude of $\mathrm{RxO}$ abuse in Europe, despite increasing public and scientific interest in the issue. The purpose of this study was to use the best-available data to derive comparable estimates of the health care burden of RxO abuse in France, Germany, Italy, Spain, and the United Kingdom (EU5).

Methods: Published data on the prevalence of problem opioid use and the share of opioid abuse patients reporting misuse of non-heroin opioids were used to estimate the prevalence of $\mathrm{RxO}$ abuse in the EU5 countries. The costs of $\mathrm{RxO}$ abuse were calculated by applying published estimates of the incremental health care costs of opioid abuse to country-specific estimates of the costs of chronic pain conditions. These estimates were input into an economic model that quantified the health care burden of $\mathrm{RxO}$ abuse in each of the EU5 countries. Sensitivity analyses examined key assumptions.

Results: Based on best-available current data, prevalence estimates of $\mathrm{RxO}$ abuse ranged from 0.7 to 13.7 per 10,000 individuals across the EU5 countries. Estimates of the incremental health care costs of $\mathrm{RxO}$ abuse ranged from $€ 900$ to $€ 2,551$ per patient per year. The annual health care cost burden of $\mathrm{RxO}$ abuse ranged from $€ 6,264$ to $€ 279,927$ per 100,000 individuals across the EU5 countries.

Conclusion: This study suggests that $\mathrm{RxO}$ abuse imposes a cost burden on health systems in the five largest European countries. The extent of $\mathrm{RxO}$ abuse in Europe should be monitored given the potential for change over time. Continued efforts should be made to collect reliable data on the prevalence and costs of $\mathrm{RxO}$ abuse in Europe to facilitate an accurate characterization of the extent of this potentially growing problem.

Keywords: prescription opioids, abuse, prevalence, health care costs

\section{Introduction}

Opioid abuse is a serious public health issue in Europe, with an estimated 1.3 million problem opioid users reported in 2012. ${ }^{1}$ In addition to the abuse of heroin and other illicit opioids, prescription opioid ("RxO") abuse also represents a component of the overall opioid abuse problem. While RxOs are among the most effective drugs for pain management, ${ }^{2}$ these medications also carry the risk of potential abuse and dependence.

$\mathrm{RxO}$ abuse has not been regarded as a major problem in Europe so far. However, there is an increasing public and scientific interest in this issue. The UK's House of Commons Home Affairs Committee has expressed concern regarding the lack of understanding and data collection surrounding the issue of prescription drug dependence. ${ }^{3}$ 
In addition, responding to the challenge of the misuse of RxOs is one of several goals set forth in the European Union Action Plan on Drugs 2013-2016. ${ }^{4}$ A research project funded by the European Commission to synthesize knowledge surrounding substance use and addictive behaviors recently released a policy brief recommending better research on the nonmedical use of RxOs in the European Union. ${ }^{5}$

While a lack of sufficient evidence regarding the magnitude of RxO abuse in Europe has hindered the assessment of this problem, available data have raised concerns about the role RxO misuse plays in the European Union. According to the European Monitoring Centre for Drugs and Drug Addiction (EMCDDA), the majority of the European countries reported over $10 \%$ of first-time opioid clients entering specialist treatment in 2012 as having misused opioids other than heroin. ${ }^{1}$ Casati et al reviewed literature on the misuse of medicines in the European Union and found that analgesics were one of the most frequently misused types of medicines. ${ }^{6}$ In a recent review comparing opioid prescribing, misuse, and overdose mortality in the US and the UK, Weisberg et al recommended that proactive steps be taken to avoid a public health crisis as prescriptions for $\mathrm{RxOs}$ in the UK increase. ${ }^{7}$

Previous studies conducted in the US have shown that $\mathrm{RxO}$ abuse imposes a significant economic burden there. Rice et al estimated the annual per patient excess health care costs of opioid abuse to be $\$ 10,627$ among commerciallyinsured individuals. ${ }^{8}$ Birnbaum et al estimated the annual health care costs of $\mathrm{RxO}$ abuse at nearly $\$ 25$ billion, with additional societal costs (eg, criminal justice costs, workplace costs associated with lost productivity) totaling nearly $\$ 31$ billion. ${ }^{9}$ Similarly, studies in Canada have found that RxO abuse is associated with a substantial economic and health care burden. ${ }^{10,11}$ As much of the literature on the health care costs of RxO abuse to date has focused on North America, further research focusing on the impact of $\mathrm{RxO}$ abuse in Europe is needed.

The purpose of this study was to derive comparable estimates of the prevalence and excess health care costs of RxO abuse in France, Germany, Italy, Spain, and the United Kingdom (EU5) using country-specific data on the prevalence of opioid abuse and the health care costs of chronic pain conditions, as well as previously published studies on the excess health care costs of opioid abuse. These estimates were input into an economic model that quantified the health care burden of $\mathrm{RxO}$ abuse in each of the EU5 countries.

\section{Materials and methods Study design and data sources}

The economic model relied on two key inputs. First, we used estimates from the EMCDDA and the United Nations Office on Drugs and Crime (UNODC) to estimate the prevalence of $\mathrm{RxO}$ abuse in each of the EU5 countries. Second, we used published estimates of the countryspecific health care costs of chronic pain conditions such as low back pain and knee osteoarthritis. As a targeted literature search yielded no published estimates of the health care costs of RxO abuse in the EU5 countries, published US-based estimates of the health care costs of opioid abuse were adapted to the EU5 countries. The estimated ratio of incremental opioid abuse costs to costs incurred by individuals without opioid abuse in the US was combined with country-specific estimates of the costs of chronic pain in the EU5 countries. By using the estimated costs of chronic pain in the EU5 countries to anchor the calculations, the model (to a first approximation) adjusted for differences in the costs of health care delivery across countries. Combining the prevalence estimates with the derived cost estimates allowed us to model the overall health care burden of $\mathrm{RxO}$ abuse in each EU5 country.

Established in 1993, the EMCDDA is a decentralized agency of the European Union that exists to provide an overview of drug problems in Europe and gather a solid evidence base surrounding drug-related issues. The EMCDDA publishes an annual report on the state of the drug use problem in Europe, as well as a statistical bulletin that provides access to recent data. Among other measures, these data include prevalence estimates by type of problem drug use and estimates of drug treatment utilization by primary drug. ${ }^{12}$

The UNODC was established in 1997 to assist United Nations member states in the struggle against illicit drugs and crime. Much like the EMCDDA, the UNODC publishes an annual report, which provides an up-to-date overview of the drug-related issues facing the world, as well as relevant statistics. $^{13}$

Data sources for the calculation of the incremental health care costs of RxO abuse included published studies from Europe and the US. Ten country-specific studies on the costs of chronic pain conditions were identified, ${ }^{14-23}$ in addition to two published studies on the costs of opioid abuse in the US. ${ }^{8,24}$ The data used in these calculations were the bestavailable data at the time these analyses were conducted. All costs were inflated to 2013 euros $(€)$. 


\section{Definition of prescription opioid abuse}

One key challenge that has hindered the accurate characterization of the RxO abuse problem in Europe is the lack of a consistent set of definitions to describe several related yet distinct behaviors, including misuse, abuse, and dependence. The Analgesic, Anesthetic, and Addiction Clinical Trials, Translations, Innovations, Opportunities and Networks (ACTTION) public-private partnership has created a set of proposed definitions to help classify various events related to the inappropriate use of prescription medications. ${ }^{25}$ The ACTTION partnership defines misuse as "any intentional therapeutic use of a drug product in an inappropriate way". Abuse is defined as "any intentional, nontherapeutic use of a drug product or substance, even once, for the purpose of achieving a desirable psychological or physiological effect". Dependence is considered to be less well-defined, and psychological dependence (eg, craving and compulsive use) is considered to overlap with abuse.

The purpose of this study was to derive estimates of the prevalence and excess health care costs of $\mathrm{RxO}$ abuse in the EU5 countries. However, due to data limitations, different inputs to the economic model were based on potentially different definitions of inappropriate $\mathrm{RxO}$ use. For example, one set of prevalence measures estimated the rate of problem opioid use among the general population, while another estimated the proportion of all clients entering drug treatment for whom opioids other than heroin were the primary substance misused. Moreover, because prevalence data were collected and reported on a country-by-country basis, the exact methodologies used to derive each set of prevalence measures were not necessarily consistent across countries. Cost estimates, however, approximated the excess costs of opioid abuse or dependence as defined using International Classification of Diseases, Ninth Revision, Clinical Modification (ICD-9-CM) diagnosis codes. For the sake of simplicity, we will define all data inputs based on the descriptions provided in the corresponding source documents, but will refer generally to this study's condition of interest as " $\mathrm{RxO}$ abuse". Individuals may abuse RxOs obtained through legal means (ie, RxOs prescribed by a physician as treatment for a chronic pain condition) or through illegal channels, and individuals who abuse RxOs may or may not be poly-substance users.

\section{Prevalence of prescription opioid abuse}

To calculate the prevalence of RxO abuse in EU5 countries, we used two measures reported in the 2013 EMCDDA statistical bulletin. ${ }^{12}$ The first of these measures was the estimated prevalence of problem opioid use as a percentage of the population aged 15-64 years. However, because problem opioid use includes both the nonmedical use of $\mathrm{RxO}$ medications and the use of non- $\mathrm{RxO}$ opioids such as heroin and opium, we also incorporated a second measure, the percentage breakdown of all treatment center clients entering treatment for opioids by primary type of opioid misused. The three possible categories of opioid misuse among treatment center clients were heroin use, misuse of methadone, and misuse of other opioids. For the purposes of our analysis, we combined the latter two categories together into a single group representing the misuse of non-heroin opioids. While patients may have misused several different drugs, they were categorized by the primary drug of misuse. This results in a conservative estimate of the share of patients who misuse non-heroin opioids, as we exclude the share of patients who misuse heroin as their primary drug of misuse yet also misuse non-heroin opioids. The prevalence of $\mathrm{RxO}$ abuse in each country was estimated as the prevalence of problem opioid use in the country multiplied by the percentage of opioid users entering treatment in the country who misuse non-heroin opioids.

Because the European countries provide prevalence estimates to the EMCDDA on an individual basis, there were some country-specific data limitations. First, the EMCDDA did not report the prevalence of problem opioid use in France. Instead, we substituted the UNODC's estimate of the prevalence of opiate use in France in 2007 as a percentage of the population aged $15-64 .{ }^{13}$ In addition, the EMCDDA did not report the breakdown of treatment center clients by type of opioid misused in Germany. Instead, we substituted the EMCDDA's breakdown of treatment center clients by type of opioid misused in Austria. Germany and Austria were among the countries with the highest per capita consumption of strong opioids in 2010, and similar trends in the level of opioid medication consumption have been seen in the two countries. These factors may affect the relative proportion of treatment center clients who report misuse of non-heroin opioids. ${ }^{26,27}$ The validity of this substitution relies on the assumption that the two countries have similar distributions of treatment center clients using heroin and non-heroin opioids.

The analysis also addressed differences in data collection methodology between countries. While we were able to obtain estimates of the prevalence of problem opioid or opiate use in each of the EU5 countries, the prevalence estimate for France included only heroin and opium use, while the estimate for 
Spain included only heroin use. To account for the fact that these estimates of problem opioid use did not include $\mathrm{RxO}$ abuse, we calculated the implied prevalence of problem opioid use (including $\mathrm{RxO}$ abuse) based on the estimates available. For example, $22.6 \%$ of treatment center clients entering treatment for opioids in France misused non-heroin opioids, while the remaining $77.4 \%$ abused heroin. Therefore, we assumed that the published estimate of the prevalence of heroin and opium use in France accounted for only $77.4 \%$ of problem opioid use. We multiplied the reported estimate by a factor of approximately 1.3 , yielding an estimate reflective of all types of problem opioid use, including abuse of heroin and opium as well as $\mathrm{RxO}$ abuse. We subsequently multiplied the implied prevalence of problem opioid use by the percentage of opioid users misusing non-heroin opioids to estimate the prevalence of $\mathrm{RxO}$ abuse.

All prevalence estimates used were from the most recent year with available data. The most recent year with available data was either 2010 or 2011 in all cases, with the exception of the aforementioned 2007 estimate of the prevalence of opiate use in France.

\section{Incremental health care costs of prescription opioid abuse}

Published studies identified through a targeted literature search on the costs of chronic pain conditions were used to estimate the annual health care costs incurred by chronic pain patients. ${ }^{14-23}$ Country-specific studies were used to account for the fact that health system structure and costs may vary across the EU5 countries. In the case of countries for which more than one relevant cost study was identified, the annual cost estimate from the most recent study was used (a full list of studies identified is provided in Table S1). All cost estimates were annualized and inflated to 2013 euros using the Harmonized Indices of Consumer Prices. ${ }^{28}$

To arrive at estimates of the incremental health care costs of $\mathrm{RxO}$ abuse in each country, we combined the aforementioned estimates of the health care costs of chronic pain conditions with an estimate of the ratio of incremental opioid abuse costs to costs incurred by individuals without opioid abuse. In a recent study conducted among a commercially-insured population in the US, Rice et al estimated the average annual per patient health care costs incurred by diagnosed opioid abusers, as well as the average annual per patient health care costs incurred by matched control patients who had no diagnoses for opioid abuse ("non-abusers"). ${ }^{8}$ The health care costs that would be incurred by an opioid abuser in the absence of abuse (ie, by a non-abuser) were assumed to be approximately equal to the health care costs incurred by a chronic pain patient. Therefore, the ratio of the incremental costs of opioid abuse to the costs incurred by non-abusers in the US was assumed to be a valid proxy for the ratio of the incremental costs of $\mathrm{RxO}$ abuse to those incurred by patients in the EU5 countries with chronic pain conditions. At the time these analyses were conducted, no studies had been published that estimated the incremental health care costs of $\mathrm{RxO}$ abuse in the EU5 countries, so this approach using US-based data on the incremental health care costs of opioid abuse represented our best approximation. The incremental health care costs of $\mathrm{RxO}$ abuse in each country were calculated as that ratio multiplied by the country-specific health care costs of chronic pain conditions.

\section{Overall burden of prescription opioid abuse}

We derived estimates of the number of $\mathrm{RxO}$ abusers in each of the EU5 countries by combining the prevalence estimates described earlier with estimates of the population aged 15-64. ${ }^{29}$ Multiplying the number of $\mathrm{RxO}$ abusers by the per patient incremental health care costs of $\mathrm{RxO}$ abuse yielded estimates of the annual health care burden of $\mathrm{RxO}$ abuse in each of the five countries. In order to facilitate a comparison between countries, we also calculated the population-adjusted cost burden in each country as the burden per 100,000 individuals aged 15-64 years. Model calculations are described in detail in the supplementary material.

\section{Sensitivity analyses}

Several key assumptions were used in the model. First, when estimating the prevalence of $\mathrm{RxO}$ abuse, the distribution of treatment center clients entering treatment for opioids by type of opioid misused was assumed the same as the distribution of opioid users by type of opioid misused among the general population. However, research in the US suggests that the percentage breakdown of treatment center clients by opioid type may understate the magnitude of $\mathrm{RxO}$ abuse relative to heroin abuse as compared to the general population. While the National Survey on Drug Use and Health (NSDUH) reported that individuals who abused or were dependent on prescription pain relievers in 2011 represented $80.6 \%$ of individuals abusing either pain relievers or heroin, ${ }^{30}$ findings from the Treatment Episode Data Set (TEDS) suggest that users of non-heroin opioids accounted for only $40.2 \%$ of treatment center admissions for opioid use in $2011 .{ }^{31}$ To account for this potential understatement, a sensitivity analysis scaled up the percentage of treatment center clients entering treatment for 
opioids who misuse non-heroin opioids using the ratio of the aforementioned estimates (ie, by a factor of 2.01).

Second, the literature on calculating the incremental health care costs of opioid abuse takes several approaches. Rice et al estimated the average annual per patient incremental health care costs of opioid abuse among a general patient population. Another study by Rossiter et al employed a methodology similar to that used by Rice et al, reporting incremental opioid abuse costs among chronic RxO users in the US. ${ }^{24}$ Using results from different studies on the costs of opioid abuse may lead to different estimates of the factor used to scale up the costs of chronic pain conditions to arrive at estimates of the incremental health care costs of $\mathrm{RxO}$ abuse in each country. Therefore, a sensitivity analysis used the estimated ratio of incremental opioid abuse costs to costs incurred by non-abusers calculated by Rossiter et al. While Rossiter et al and Rice et al estimated similar excess costs of opioid abuse $(\$ 9,456$ in medical costs vs $\$ 10,627$ in combined medical and pharmacy costs), the estimated ratio of incremental opioid abuse costs to costs incurred by non-abusers was lower in Rossiter et al than in Rice et al (33\% vs 109\%). This difference reflected higher overall health care costs among chronic $\mathrm{RxO}$ users as compared to a general patient population.

Finally, to account for variability in estimates of the costs of chronic pain across studies from the same country, a sensitivity analysis used the lowest identified estimate of the annual health care costs of chronic pain conditions for those countries for which more than one relevant cost study was identified.

\section{Results}

\section{Prevalence of prescription opioid abuse}

The prevalence of $\mathrm{RxO}$ abuse varied across the EU5 countries (Table 1). France had the highest estimated prevalence at 13.7 per 10,000 individuals aged 15-64 years. Germany and the UK had similar rates of $\mathrm{RxO}$ abuse (11.0 and 10.7 per 10,000 individuals, respectively). Whereas Germany had a lower prevalence of overall problem opioid use $(0.32 \%)$ and a higher percentage of opioid users entering treatment who misuse non-heroin opioids $(34.7 \%)$, the UK had a higher problem opioid use prevalence $(0.82 \%)$ but a lower percentage of opioid users who misuse non-heroin opioids $(13.1 \%)$. Italy and Spain had the lowest $\mathrm{RxO}$ abuse prevalence of the five countries ( 0.8 and 0.7 per 10,000 individuals, respectively).

\section{Incremental health care costs of prescription opioid abuse}

Estimates of the per patient annual incremental health care costs of $\mathrm{RxO}$ abuse (Figure 1) ranged from $€ 900$ to $€ 2,551$ (France, €1,737; Germany, €2,551; Italy, €1,437; Spain, $€ 900$; UK, €1,501).

\section{Overall burden of prescription opioid abuse}

The combination of the estimates of the prevalence and incremental health care costs of $\mathrm{RxO}$ abuse with population estimates for each country ${ }^{29}$ yielded estimates of the overall health care burden of RxO abuse by country. A detailed account of the aggregate country-level calculations is provided in Table 2. Across the EU5 countries, the annual health care cost burden of $\mathrm{RxO}$ abuse ranged from $€ 2.0$ million to $€ 152.9$ million (France, $€ 97.9$ million; Germany, €152.9 million; Italy, €4.3 million; Spain, $€ 2.0$ million; UK, €65.7 million). Adjusting for population (Figure 2), the annual health care costs of $\mathrm{RxO}$ abuse per 100,000 individuals aged 15-64 years ranged from $€ 6,264$ to $€ 279,927$ (France, $€ 238,691$; Germany, $€ 279,927$; Italy, $€ 10,901$; Spain, €6,264; UK, €160,835).

\section{Sensitivity analyses}

Sensitivity analyses examined the effect of the assumptions on the results described earlier (Table 2) (a more detailed

Table I Prevalence of $\mathrm{RxO}$ abuse

\begin{tabular}{|c|c|c|c|c|c|}
\hline Estimate & France & Germany & Italy & Spain & United Kingdom \\
\hline \multicolumn{6}{|l|}{$A_{i}$} \\
\hline $\begin{array}{l}\text { Prevalence of problem opioid use } \\
\text { (\% of population aged } 15-64 \text { years) }\end{array}$ & 0.61 & 0.32 & 0.48 & 0.12 & 0.82 \\
\hline \multicolumn{6}{|l|}{$B$} \\
\hline $\begin{array}{l}\text { Percentage who misuse non-heroin opioids } \\
\text { (\% of opioid users entering treatment) }\end{array}$ & 22.6 & 34.7 & 1.6 & 5.7 & 13.1 \\
\hline \multicolumn{6}{|l|}{$C_{i}=A_{i} \times B_{i}$} \\
\hline $\begin{array}{l}\text { Prevalence of } \mathrm{RxO} \text { abuse (per } 10,000 \\
\text { individuals aged } 15-64 \text { years) }\end{array}$ & 13.7 & 11.0 & 0.8 & 0.7 & 10.7 \\
\hline
\end{tabular}

Abbreviation: $\mathrm{RxO}$, prescription opioid. 


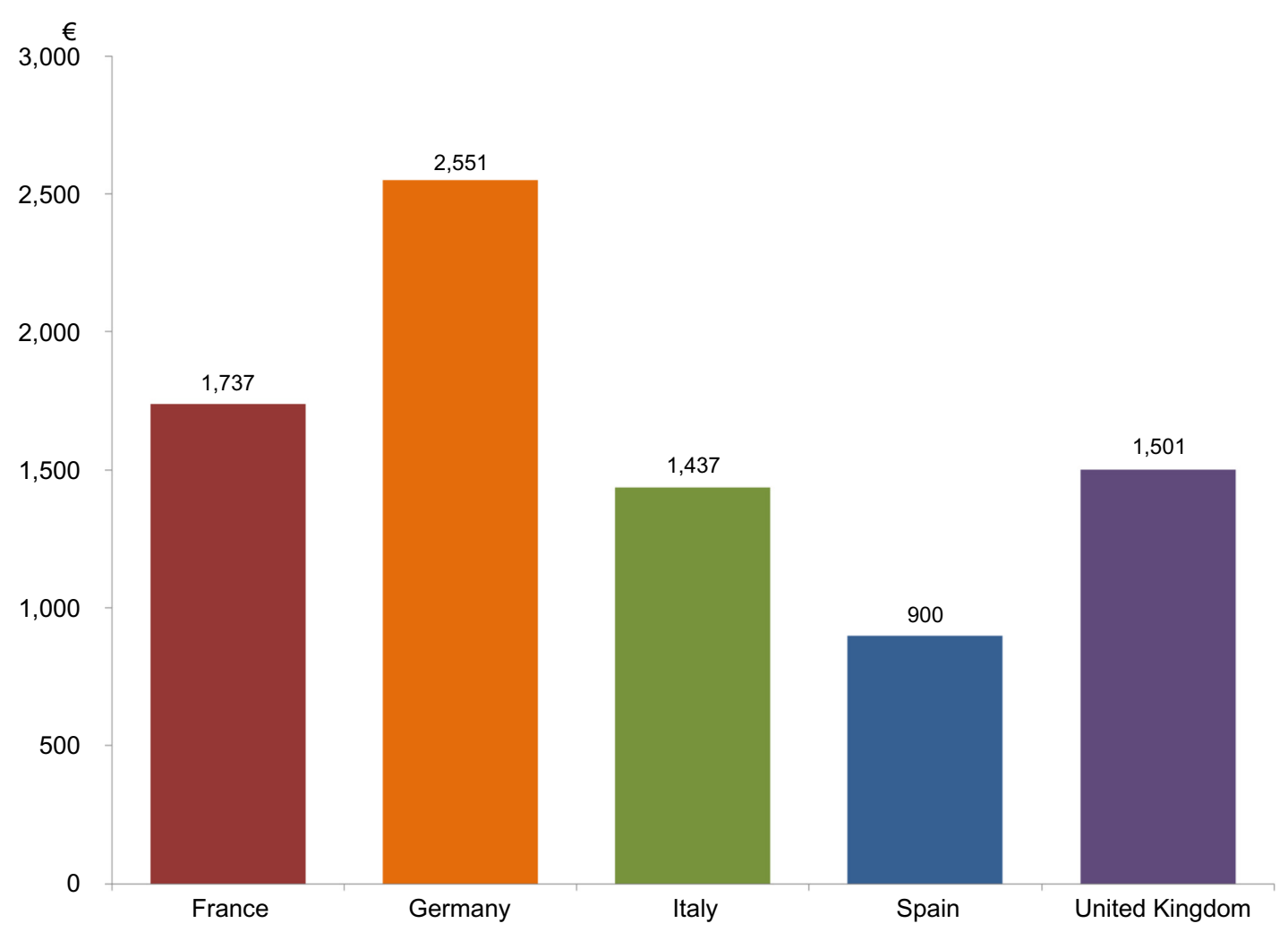

Figure I Per patient annual incremental health care costs of $\mathrm{RxO}$ abuse.

Note: All costs are reported in 2013 euros.

Abbreviation: $\mathrm{R} \times \mathrm{O}$, prescription opioid.

Table 2 Overall annual health care burden of $\mathrm{RxO}$ abuse: core results and summary of sensitivity analyses

\begin{tabular}{|c|c|c|c|c|c|}
\hline Estimate & France & Germany & Italy & Spain & $\begin{array}{l}\text { United } \\
\text { Kingdom }\end{array}$ \\
\hline \multicolumn{6}{|l|}{$C_{i}$} \\
\hline $\begin{array}{l}\text { Prevalence of } \mathrm{RxO} \text { abuse (\% of population aged } \\
15-64 \text { years) }\end{array}$ & 0.137 & 0.110 & 0.008 & 0.007 & 0.107 \\
\hline \multicolumn{6}{|l|}{$K_{i}$} \\
\hline$J_{i}$ Population aged $15-64$ years in 2010 (thousands) & $4 I, 001$ & 54,610 & 39,735 & 31,389 & 40,871 \\
\hline $\begin{array}{l}\text { Per patient annual incremental health care costs } \\
\text { of } \mathrm{RxO} \text { abuse }\end{array}$ & $€ 1,737$ & $€ 2,55$ I & $€ 1,437$ & $€ 900$ & $€ 1,50 \mid$ \\
\hline$L_{i}=C_{i} \times K_{i} \times J_{i}$ & & & & & \\
\hline Annual health care burden of $\mathrm{RxO}$ abuse & $€ 97.9$ million & $€ I 52.9$ million & $€ 4.3$ million & $€ 2.0$ million & $€ 65.7$ million \\
\hline$M_{i}=\left(L_{i} / K_{i}\right) \times 100,000$ & & & & & \\
\hline Annual health care burden of $\mathrm{R} \times \mathrm{O}$ abuse, per & $€ 238,691$ & $€ 279,927$ & $€|0,90|$ & $€ 6,264$ & $€ 160,835$ \\
\hline
\end{tabular}

100,000 individuals aged $15-64$ years

Sensitivity A Higher estimate of the percentage of opioid users entering treatment who misuse non-heroin opioids $L_{i}^{*}=C_{i}^{*} \times K_{i} \times J_{i}$

Annual health care burden of $\mathrm{R} \times \mathrm{O}$ abuse

$€ 278$. I million

$€ 306.7$ million

$€ 8.7$ million

$€ 4.2$ million

$€|3| .9$ million

Sensitivity B Lower ratio of incremental health care costs of $\mathrm{RxO}$ abusers to those of matched control patients $L_{i}^{\#}=C_{i} \times K_{i} \times J_{i}^{\#}$

Annual health care burden of $\mathrm{RxO}$ abuse

$€ 29.8$ million $\quad € 46.6$ million

$€ 1.3$ million

$€ 0.6$ million

$€ 20.0$ million

Sensitivity C Lower estimates of the annual health care costs of chronic pain conditions $L_{i}^{\ddagger}=C_{i} \times K_{i} \times J_{i}^{\ddagger}$

Annual health care burden of $\mathrm{RxO}$ abuse

$€ 97.9$ million

$€ 46.3$ million

$€ 2.4$ million

$€ I .3$ million

$€ 65.7$ million

Notes: All costs are reported in 2013 euros. Calculations for sensitivity A, sensitivity B, and sensitivity C are denoted with *, , and ${ }^{\ddagger}$, respectively.

Abbreviation: $\mathrm{RxO}$, prescription opioid. 


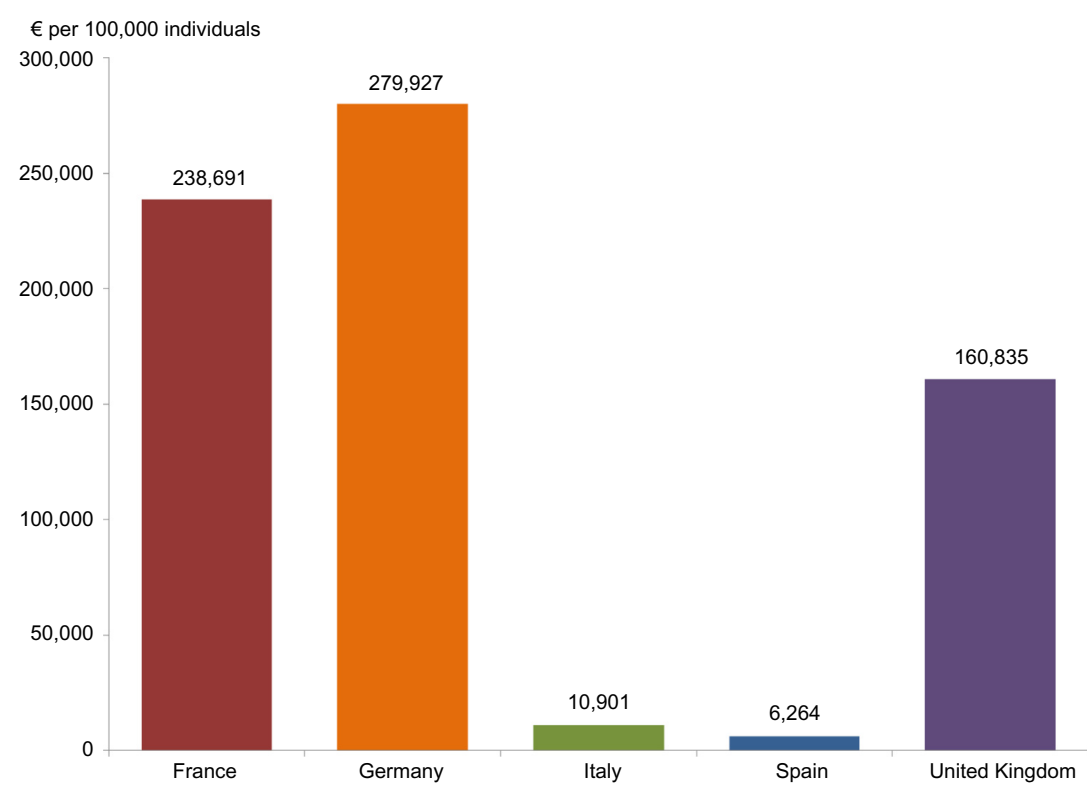

Figure 2 Population-adjusted annual health care burden of $\mathrm{RxO}$ abuse.

Note: All costs are reported in 2013 euros.

Abbreviation: $\mathrm{RxO}$, prescription opioid.

account of the aggregate country-level calculations for the sensitivity analyses is provided in Table S2). After the application of the prevalence rate adjustment to account for the potential understatement of the magnitude of $\mathrm{RxO}$ abuse relative to heroin abuse as a result of the use of treatment center data, the annual health care burden of RxO abuse in the EU5 countries ranged from $€ 4.2$ million to $€ 306.7$ million.

After the application of the alternate (lower) ratio of incremental opioid abuse costs to costs incurred by nonabusers as calculated by Rossiter et al to the country-specific estimates of the costs of chronic pain conditions, the annual health care burden of $\mathrm{RxO}$ abuse ranged from $€ 0.6$ million to $€ 46.6$ million.

Using the lowest estimates of the health care costs of chronic pain conditions identified through the targeted literature search, the annual health care burden of $\mathrm{RxO}$ abuse ranged from $€ 1.3$ million to $€ 97.9$ million. Cost estimates for France and the UK remained unchanged for the purposes of this sensitivity analysis, as only one relevant publication was identified for each country.

\section{Discussion}

There may be several reasons for the variation across the EU5 countries in terms of the overall health care cost burden of $\mathrm{RxO}$ abuse. The overall volume of $\mathrm{RxO}$ prescriptions varies by country, ${ }^{26,27}$ affecting the availability of potentially abusable medications. Differences in rates of opioid consumption may stem from various sources, including health care systems and regulations that make it more or less difficult for physicians to prescribe RxOs, as well as physician and patient attitudes toward the use of RxOs in pain management. The cost burden of $\mathrm{RxO}$ abuse may additionally be affected by the country-specific availability of alternative drugs of abuse, in particular heroin. Importantly, the differences reported in this study may also reflect variation in the methodology and quality of abuse prevalence data in the five countries. As such, any cross-country comparisons should be interpreted with caution.

While the prevalence of $\mathrm{RxO}$ abuse in Europe may be relatively low at the present time, further research is necessary to determine whether there is any trend over time. Zin et al found that prescriptions for strong opioids increased significantly in the UK between 2000 and 2010, as did the average number of prescriptions per patient. ${ }^{32}$ International Narcotics Control Board (INCB) data on $\mathrm{RxO}$ consumption over time suggest that consumption of $\mathrm{RxOs}$ in the UK in 2012 reached the same levels as $\mathrm{RxO}$ consumption in 2000 in the US. These data suggest an increase in $\mathrm{RxO}$ consumption over time in the other EU5 countries as well. ${ }^{27}$ In addition, estimates published by the EMCDDA suggest an increasing trend in $\mathrm{RxO}$ abuse over time. In the UK, 8,963 drug treatment center clients reported non-heroin opioids as their primary drug in 2010 , more than a $60 \%$ increase compared to $2004 .^{12,33}$ The experience in the US further supports the idea that the 
magnitude of the $\mathrm{RxO}$ abuse problem has the potential to increase quite rapidly, as the prevalence there has doubled from $0.4 \%$ in 2002 to $0.8 \%$ in $2012 .^{30,34}$

Given the possibility of an increase in the prescription of RxOs over time, the introduction of new technologies such as abuse-deterrent $\mathrm{RxO}$ formulations (ADFs) is one approach that has been taken in an attempt to lessen the burden of $\mathrm{RxO}$ abuse. Rossiter et al examined the prevalence of opioid abuse in the US before and after the introduction of reformulated extended-release (ER) oxycodone, finding that the introduction of reformulated ER oxycodone was associated with a $22.7 \%$ relative reduction in opioid abuse rates among commercially-insured chronic RxO users. ${ }^{24}$ Sessler et al also reported an $82 \%$ decrease in the number of fatalities reported to the manufacturer from the year before the reformulation of ER oxycodone to the 3 rd year after reformulation, suggesting that the abuse-deterrent properties of ER oxycodone have decreased the number of deaths associated with the drug's misuse and abuse. ${ }^{35}$ In addition, a prolonged-release formulation of oxycodone/naloxone, which has been approved in many European countries, may provide abuse deterrence. ${ }^{36,37}$ ADFs are an important component of the ongoing effort to decrease the prevalence of $\mathrm{RxO}$ abuse.

While $\mathrm{RxO}$ abuse in the EU5 countries is a problem with the potential to increase over time, our estimates of the prevalence of $\mathrm{RxO}$ abuse in the EU5 countries are much lower than previously published estimates of the prevalence of $\mathrm{RxO}$ abuse in the US. The NSDUH estimated that approximately 2 million individuals in the US (0.8\%) abused or were dependent on prescription pain relievers in $2012,{ }^{30}$ whereas we estimate a combined total of approximately 165,000 individuals with $\mathrm{RxO}$ abuse in the EU5 countries $(0.1 \%)$. Estimates of the incremental health care costs of abuse are also lower in the EU5 countries than in the US. The estimated incremental costs of opioid abuse in the US as reported by Rice et al are equivalent to $€ 8,396$ in 2013 euros. ${ }^{8,28,38}$ This estimate is considerably higher than even the highest estimated incremental cost of $\mathrm{RxO}$ abuse in the EU5 countries ( $€ 2,551$ in Germany), although this difference may in part reflect higher costs of care in the US. More robust monitoring and data collection surrounding the issue of $\mathrm{RxO}$ abuse in the EU5 countries are important steps toward preventing the escalation of this problem.

Finally, while this study focused on the health care costs of RxO abuse in the EU5 countries, evidence from the published literature suggests that the overall societal costs of $\mathrm{RxO}$ abuse may be far greater than health care costs alone. Less than half of the nearly $\$ 56$ billion in total annual societal costs of RxO abuse in the US calculated by Birnbaum et al were attributable to direct health care costs, with criminal justice costs totaling over $\$ 5$ billion and costs of lost workplace productivity contributing an additional $\$ 26$ billion. ${ }^{9}$ Future research should also consider the potentially substantial indirect costs of $\mathrm{RxO}$ abuse in the EU5 countries.

\section{Limitations}

This study had several limitations. First, because no single data source reported the prevalence of $\mathrm{RxO}$ abuse in the EU5 countries, it was necessary to combine two separate prevalence estimates based on different populations. The EMCDDA data on the type of opioid misused by treatment center clients entering treatment for opioids used in this study capture only those treatment center patients for whom $\mathrm{RxO}$ are the primary drug of abuse. As further data on the prevalence of $\mathrm{RxO}$ abuse in Europe are collected, more reliable estimates of the prevalence of abuse will allow for more accurate estimation of the potential cost burden. Another limitation of the available prevalence data was potential inconsistency in the definitions of inappropriate $\mathrm{RxO}$ use (ie, abuse, misuse). Use of explicitly defined and consistent definitions will ease interpretation of future prevalence estimates. In addition, while the most recent prevalence estimates available were used, 2007 was the most recent year for which the estimated prevalence of opiate use in France was available. As more recent reports suggest that the prevalence of illicit opioid use has declined in Western Europe in recent years, ${ }^{39,40}$ the 2007 estimate may not reflect the current prevalence of opiate use in France, which could affect our results.

In estimating the health care burden of $\mathrm{RxO}$ abuse, we assumed that the costs of non-abusers (ie, control patients matched to diagnosed opioid abusers) were comparable to those of chronic pain patients, and that the ratio of incremental opioid abuse costs to costs incurred by non-abusers could therefore be applied to estimates of chronic pain costs in order to estimate the incremental health care costs of $\mathrm{RxO}$ abuse. We also assumed that various estimates based on studies conducted in the US were applicable to the EU5 countries considered in this study, including the aforementioned ratio of incremental opioid abuse costs to costs incurred by non-abusers and the relative magnitude of $\mathrm{RxO}$ abuse among treatment center clients as compared to the general population. However, these US-based estimates may not be representative of the EU5 countries. Once again, further collection of accurate data surrounding the abuse of RxOs in Europe will help produce more accurate estimates of the cost burden of $\mathrm{RxO}$ abuse in the future. 


\section{Conclusion}

While RxO abuse has not been regarded as a major problem in Europe so far, this potentially growing problem has garnered increasing interest in recent years. This study suggests that $\mathrm{RxO}$ abuse has an impact on health systems in the EU5 countries, with estimated annual health system costs ranging from $€ 2.0$ million to $€ 152.9$ million. Given the potential for change over time, the $\mathrm{RxO}$ abuse problem in Europe should be closely monitored. Continued efforts to collect reliable data on the prevalence and health care costs of $\mathrm{RxO}$ abuse in the European countries will allow both researchers and policymakers to more accurately characterize the extent of the problem, as well as introduce necessary policy interventions in a timely manner.

\section{Acknowledgment}

The authors wish to acknowledge the contributions of Rami Ben-Joseph, $\mathrm{PhD}$, to the overall inception and design of this project. Dr Ben-Joseph is an employee of Purdue Pharma LP.

\section{Disclosure}

This study was funded by Mundipharma International Limited. MH and WCND are employees of Mundipharma International Limited; AS, NYK, CJE, and HGB are employees of Analysis Group, Inc., a consulting company that received funding for this research from Mundipharma International Limited. The authors report no other conflicts of interest in this work.

\section{References}

1. European Monitoring Centre for Drugs and Drug Addiction. European Drug Report 2014: Trends and Developments. Luxembourg: Publications Office of the European Union; 2014.

2. Volkow ND, McLellan TA. Curtailing diversion and abuse of opioid analgesics without jeopardizing pain treatment. JAMA. 2011;290: 2443-2454.

3. House of Commons Home Affairs Committee. Drugs: New Psychoactive Substances and Prescription Drugs. London: The Stationery Office Limited; 2013. Available from: http://www.publications.parliament. uk/pa/cm201314/cmselect/cmhaff/819/819.pdf. Accessed August 7, 2014.

4. European Union (EU) Council. EU Action Plan on Drugs 2013-2016. OJEC C 351/1, November 30, 2013. Available from: http://eur-lex.europa. eu/LexUriServ/LexUriServ.do?uri=OJ:C:2013:351:0001:0023:en:PDF. Accessed September 12, 2014.

5. Rehm J. Prescription Opioids and Public Health in the European Union. ALICE RAP Policy Paper Series, Policy Brief 4. Available from: http:// www.alicerap.eu/resources/documents/cat_view/1-alice-rap-projectdocuments/19-policy-paper-series.html. Accessed August 11, 2014.

6. Casati A, Sedefov R, Pfeiffer-Gerschel T. Misuse of medicines in the European Union: a systematic review of the literature. Eur Addict Res. 2012;18(5):228-245.

7. Weisberg DF, Becker WC, Fiellin DA, et al. Prescription opioid misuse in the United States and the United Kingdom: cautionary lessons. Int J Drug Policy. 2014;25(6):1124-1130.
8. Rice JB, Kirson NY, Shei A, et al. Estimating the costs of opioid abuse and dependence from an employer perspective: a retrospective analysis using administrative claims data. Appl Health Econ Health Policy. 2014;12(4):435-446.

9. Birnbaum HG, White AG, Schiller M, et al. Societal costs of prescription opioid abuse, dependence, and misuse in the United States. Pain Med. 2011;12(4):657-667.

10. Fischer B, Gooch J, Goldman B, et al. Non-medical prescription opioid use, prescription opioid-related harms and public health in Canada: an update 5 years later. Can J Public Health. 2014;105(2): e146-e149.

11. Skinner BJ. Net Societal Economic Impact in Canada from Withholding Regulatory Approval for Generic Oxycontin ${ }^{\circledR}$. Canadian Health Policy, September 12, 2012. Toronto, ON: Canadian Health Policy Institute; 2012

12. European Monitoring Centre for Drugs and Drug Addiction. Statistical Bulletin, 2013. Available from: http://www.emcdda.europa.eu/stats13. Accessed January 15, 2014.

13. United Nations Office on Drugs and Crime. World Drug Report 2010. Available from: http://www.unodc.org/documents/wdr/WDR_2010/ World_Drug_Report_2010_lo-res.pdf. Accessed January 21, 2014.

14. Depont F, Hunsche E, Abouelfath A, et al. Medical and non-medical direct costs of chronic low back pain in patients consulting primary care physicians in France. Fundam Clin Pharmacol. 2010;24(1): 101-108.

15. Langley PC. The societal burden of pain in Germany: health-related quality-of-life, health status and direct medical costs. J Med Econ. 2012;15(6):1201-1215.

16. Colombo GL, Caruggi M, Vinci M. Quality of life and treatment costs in patients with non-cancer chronic pain. Recenti Prog Med. 2004;95(11):512-520.

17. Loza E, Lopez-Gomez JM, Abasolo L, et al. Economic burden of knee and hip osteoarthritis in Spain. Arthritis Rheum. 2009;61(2):158-165.

18. Hong J, Reed C, Novick D, et al. Costs associated with treatment of chronic low back pain: an analysis of the UK General Practice Research Database. Spine (Phila Pa 1976). 2013;38(1):75-82.

19. Wenig CM, Schmidt CO, Kohlmann T, et al. Costs of back pain in Germany. Eur J Pain. 2008;13(3):280-286.

20. Leardini G, Salaffi F, Caporali R, et al. Direct and indirect costs of osteoarthritis of the knee. Clin Exp Rheumatol. 2004;22(6) 699-706.

21. Núñez M, Núñez E, Segur JM, et al. Health-related costs in patients with osteoarthritis on waiting list for total knee replacement. Osteoarthritis Cartilage. 2007;15(3):258-265.

22. Becker A, Held H, Redaelli M, et al. Low back pain in primary care: costs of care and prediction of future health care utilization. Spine (Phila Pa 1976). 2010;35(18):1714-1720.

23. Becker A, Seitz R, Jacobi E, et al. [Cost evaluation by a patient questionnaire: pilot study of a weekly cost diary]. Rehabilitation (Stuttg). 2001;40(1):12-20.

24. Rossiter LF, Kirson NY, Shei A, et al. Medical cost savings associated with an extended-release opioid with abuse-deterrent technology in the US. J Med Econ. 2014;17(4):279-287.

25. Smith SM, Dart RC, Katz NP, et al. Classification and definition of misuse, abuse, and related events in clinical trials: ACTTION systematic review and recommendations. Pain. 2013;154(11):2287-2296.

26. Von Korff MR. Long-term use of opioids for complex chronic pain. Best Pract Res Clin Rheumatol. 2013;27(5):663-672.

27. Pain \& Policy Studies Group. Opioid Consumption Data. Madison, WI University of Wisconsin Pain and Policy Studies Group. Available from: http://www.painpolicy.wisc.edu/opioid-consumption-data. Accessed September 16, 2014

28. European Commission. Eurostat, Harmonised Indices of Consumer Prices (HICP). Available from: http://epp.eurostat.ec.europa.eu/portal/ page/portal/hicp/data/database. Accessed February 12, 2014.

29. UN Data. Statistics, Population Aged 15-64 (Thousands). Available from: http://data.un.org/Data.aspx?d=PopDiv\&f=variableID\%3A88. Accessed February 12, 2014. 
30. Substance Abuse and Mental Health Services Administration. Results from the 2012 National Survey on Drug Use and Health: Summary of National Findings, NSDUH Series H-46, HHS Publication No (SMA) 13-4795. Rockville, MD: Substance Abuse and Mental Health Services Administration; 2013.

31. Substance Abuse and Mental Health Services Administration, Center for Behavioral Health Statistics and Quality. Treatment Episode Data Set (TEDS): 2001-2011. National Admissions to Substance Abuse Treatment Services, BHSIS Series S-65, HHS Publication No (SMA) 13-4772. Rockville, MD: Substance Abuse and Mental Health Services Administration; 2013.

32. Zin CS, Chen LC, Knaggs RD. Changes in trends and pattern of strong opioid prescribing in primary care. Eur J Pain. 2014;18(9): 1343-1351.

33. European Monitoring Centre for Drugs and Drug Addiction. Statistical Bulletin; 2006. Available from: http://stats06.emcdda.europa.eu/en/ home-en.html. Accessed September 17, 2014.

34. Substance Abuse and Mental Health Services Administration. Results from the 2002 National Survey on Drug Use and Health: National Findings, NHSDA Series H-22, DHHS Publication No SMA03-3836. Rockville, MD: Substance Abuse and Mental Health Services Administration; 2003.
35. Sessler NE, Downing JM, Hrishikesh K, et al. Reductions in reported deaths following the introduction of extended-release oxycodone (OxyContin) with an abuse-deterrent formulation. Pharmacoepidemiol Drug Saf. 2014;23(12):1238-1246.

36. DePriest AZ, Miller K. Oxycodone/naloxone: role in chronic pain management, opioid-induced constipation, and abuse deterrence. Pain Ther. 2014;3(1):1-15.

37. Targiniq ER. Prescribing Information. Stamford, CT: Purdue Pharma LP. Available from: http://www.accessdata.fda.gov/drugsatfda_docs/ label/2014/205777lbl.pdf. Accessed October 6, 2014.

38. European Central Bank. Statistical Data Warehouse, Exchange Rates. Available from: http://sdw.ecb.europa.eu/. Accessed August 11, 2014.

39. United Nations Office on Drugs and Crime. World Drug Report 2013. Available from: http:/www.unodc.org/unodc/secured/wdr/wdr2013/ World_Drug_Report_2013.pdf. Accessed May 7, 2015.

40. United Nations Office on Drugs and Crime. World Drug Report 2014. Available from: http://www.unodc.org/documents/wdr2014/ World_Drug_Report_2014_web.pdf. Accessed May 7, 2015. 


\section{Supplementary materials Model calculations}

The following equations describe the precise calculations underlying the economic model.

Step 1: Prevalence of prescription opioid ( $\mathrm{RxO})$ abuse. $A_{i}=$ Prevalence of problem opioid use in country $i(\%)$

$A_{i}^{*}=$ Prevalence of problem opioid use (excluding $\mathrm{RxO}$ abuse) in country $i(\%)$

$B_{i}=$ Percentage of opioid users entering treatment in country $i$ who misuse non-heroin opioids (\%)

$C_{i}=A_{i} \times B_{i}=$ Prevalence of RxO abuse in country $i(\%)$

Note: In countries for which the prevalence of problem opioid use excluding $\mathrm{RxO}$ abuse was reported (ie, France and Spain), $A_{i}$ was scaled up using the estimated percentage of opioid users entering treatment who misuse non-heroin opioids: $A_{i}=A_{i}^{*} /\left(1-B_{i}\right)$.
Step 2: Health care costs of chronic pain conditions.

$D_{i}=$ Health care costs of chronic pain conditions in country $i$ (euros)

$E_{i}=$ Harmonized Indices of Consumer Prices (HICP) inflation factor

$F_{i}=D_{i} \times E_{i}=$ Adjusted health care costs of chronic pain conditions in country $i$ (2013 euros)

Note: In addition to the adjustment of all cost estimates to account for inflation, estimated costs in the UK were converted from pound sterling $(£)$ to euros $(€) .{ }^{1}$

Step 3: Incremental health care costs of RxO abuse.

$G=$ Health care costs incurred by $\mathrm{RxO}$ abusers in the US (2012 US dollars)

$H=$ Health care costs incurred by non-abusers in the US (2012 US dollars)

$J_{i}=F_{i} \times[(G-H) / H]=$ Incremental health care costs of $\mathrm{RxO}$ abuse in country $i$ (2013 euros).

Table SI Published studies on the costs of chronic pain conditions in the EU5 countries

\begin{tabular}{|c|c|c|c|}
\hline Country & Study & Title & Annual cost estimate \\
\hline France & Depont et al ${ }^{14}$ & $\begin{array}{l}\text { Medical and non-medical direct costs of chronic low back pain in patients } \\
\text { consulting primary care physicians in France }\end{array}$ & $€ 1,588$ \\
\hline \multirow[t]{4}{*}{ Germany } & Langley ${ }^{15}$ & $\begin{array}{l}\text { The societal burden of pain in Germany: health-related quality-of-life, health } \\
\text { status, and direct medical costs }\end{array}$ & $€ 2,333$ \\
\hline & Becker et $\mathrm{a}^{22}$ & $\begin{array}{l}\text { Low back pain in primary care: costs of care and prediction of future health } \\
\text { care utilization }\end{array}$ & $€ 2,007$ \\
\hline & Wenig et al ${ }^{19}$ & Costs of back pain in Germany & $€ 706$ \\
\hline & Becker et $\mathrm{a}^{23}$ & Cost evaluation by a patient questionnaire: pilot study of a weekly cost diary & $€ 2,030$ \\
\hline \multirow[t]{2}{*}{ Italy } & Colombo et $\mathrm{al}^{16}$ & Quality of life and treatment costs in patients with non-cancer chronic pain & $€ 1,3 \mid 4$ \\
\hline & Leardini et $\mathrm{a}^{20}$ & Direct and indirect costs of osteoarthritis of the knee & $€ 715$ \\
\hline \multirow[t]{2}{*}{ Spain } & Loza et $\mathrm{al}^{17}$ & Economic burden of knee and hip osteoarthritis in Spain & $€ 822$ \\
\hline & Núñez et $\mathrm{al}^{2 !}$ & $\begin{array}{l}\text { Health-related costs in patients with osteoarthritis on waiting list for total } \\
\text { knee replacement }\end{array}$ & $€ 55 I$ \\
\hline UK & Hong et a $\left.\right|^{18}$ & $\begin{array}{l}\text { Costs associated with treatment of chronic low back pain: an analysis of the } \\
\text { UK General Practice Research Database }\end{array}$ & $€ 1,372$ \\
\hline
\end{tabular}

Note: All costs are reported in 2013 euros.

Abbreviation: EU5, France, Germany, Italy, Spain, and the United Kingdom. 
Table S2 Overall annual health care burden of RxO abuse: sensitivity analyses

\begin{tabular}{|c|c|c|c|c|c|}
\hline Estimate & France & Germany & Italy & Spain & $\begin{array}{l}\text { United } \\
\text { Kingdom }\end{array}$ \\
\hline \multicolumn{6}{|c|}{ Sensitivity A Higher estimate of the percentage of opioid users entering treatment who misuse non-heroin opioids } \\
\hline \multicolumn{6}{|c|}{$C_{i}^{*}$} \\
\hline $\begin{array}{l}\text { Prevalence of } \mathrm{RxO} \text { abuse (\% of population aged } \\
15-64 \text { years) }\end{array}$ & 0.391 & 0.220 & 0.015 & 0.015 & 0.215 \\
\hline \multicolumn{6}{|l|}{$K_{i}$} \\
\hline Population aged I5-64 years in 2010 (thousands) & $4 I, 001$ & 54,610 & 39,735 & 31,389 & 40,871 \\
\hline \multicolumn{6}{|l|}{$J_{i}$} \\
\hline $\begin{array}{l}\text { Per patient annual incremental health care costs } \\
\text { of } R \times O \text { abuse }\end{array}$ & $€ \mathrm{I}, 737$ & $€ 2,55$ I & $€ \mathrm{I}, 437$ & $€ 900$ & $€ I, 50 \mid$ \\
\hline \multicolumn{6}{|l|}{$L_{i}^{*}=C_{i}^{*} \times K_{i} \times J_{i}$} \\
\hline Annual health care burden of $\mathrm{RxO}$ abuse & $€ 278 . I$ million & $€ 306.7$ million & $€ 8.7$ million & $€ 4.2$ million & $€|3| .9$ million \\
\hline \multicolumn{6}{|c|}{ Sensitivity B Lower ratio of incremental health care costs of $\mathrm{R} \times \mathrm{O}$ abusers to those of matched control patients } \\
\hline \multicolumn{6}{|c|}{$C_{i}$} \\
\hline $\begin{array}{l}\text { Prevalence of } \mathrm{RxO} \text { abuse (\% of population aged } \\
\text { 15-64 years) }\end{array}$ & 0.137 & 0.110 & 0.008 & 0.007 & 0.107 \\
\hline \multicolumn{6}{|l|}{$K_{i}$} \\
\hline Population aged I5-64 years in 2010 (thousands) & $4 I, 00 I$ & 54,610 & 39,735 & 31,389 & 40,871 \\
\hline \multicolumn{6}{|l|}{$J_{i}^{\#}$} \\
\hline $\begin{array}{l}\text { Per patient annual incremental health care costs } \\
\text { of } \mathrm{RxO} \text { abuse }\end{array}$ & $€ 529$ & $€ 777$ & $€ 438$ & $€ 274$ & $€ 457$ \\
\hline \multicolumn{6}{|l|}{$L_{i}^{\#}=C_{i} \times K_{i} \times J_{i}^{\#}$} \\
\hline Annual health care burden of $\mathrm{R} \times \mathrm{O}$ abuse & $€ 29.8$ million & $€ 46.6$ million & $€ I .3$ million & $€ 0.6$ million & $€ 20.0$ million \\
\hline \multicolumn{6}{|c|}{ Sensitivity C Lower estimates of the annual health care costs of chronic pain conditions } \\
\hline \multicolumn{6}{|c|}{$C_{i}$} \\
\hline $\begin{array}{l}\text { Prevalence of } \mathrm{RxO} \text { abuse (\% of population aged } \\
15-64 \text { years) }\end{array}$ & 0.137 & 0.110 & 0.008 & 0.007 & 0.107 \\
\hline \multicolumn{6}{|l|}{$K_{i}$} \\
\hline Population aged I5-64 years in 2010 (thousands) & $4 I, 00 I$ & 54,610 & 39,735 & 31,389 & 40,871 \\
\hline \multicolumn{6}{|l|}{$J_{i}^{\neq}$} \\
\hline $\begin{array}{l}\text { Per patient annual incremental health care costs } \\
\text { of } \mathrm{RxO} \text { abuse }\end{array}$ & $€ \mathrm{I}, 737$ & $€ 772$ & $€ 783$ & $€ 603$ & $€ I, 50 \mid$ \\
\hline \multicolumn{6}{|l|}{$L_{i}^{\ddagger}=C_{i} \times K_{i} \times J_{i}^{\ddagger}$} \\
\hline Annual health care burden of $\mathrm{RxO}$ abuse & $€ 97.9$ million & $€ 46.3$ million & $€ 2.4$ million & $€ I .3$ million & $€ 65.7$ million \\
\hline
\end{tabular}

Notes: All costs are reported in 2013 euros. Calculations for sensitivity A, sensitivity B, and sensitivity C are denoted with *, \#, and $\neq$, respectively.

Abbreviation: $\mathrm{RxO}$, prescription opioid.

Step 4: Annual health care burden of $\mathrm{RxO}$ abuse.

$K_{i}=$ Population aged 15-64 years in country $i$

$L_{i}=C_{i} \times K_{i} \times J_{i}=$ Annual health care burden of $\mathrm{RxO}$ abuse in country $i$ (2013 euros)

Step 5: Population adjustments.

$M_{i}=\left(L_{i} / K_{i}\right) \times 100,000=$ Annual health care burden of $\mathrm{RxO}$ abuse per 100,000 individuals in country $i$ (2013 euros)

\section{Reference}

1. European Central Bank. Statistical Data Warehouse, Exchange Rates. Available from: http://sdw.ecb.europa.eu/. Accessed August 11, 2014.
ClinicoEconomics and Outcomes Research

\section{Publish your work in this journal}

ClinicoEconomics \& Outcomes Research is an international, peerreviewed open-access journal focusing on Health Technology Assessment, Pharmacoeconomics and Outcomes Research in the areas of diagnosis, medical devices, and clinical, surgical and pharmacological intervention. The economic impact of health policy and health systems

\section{Dovepress}

organization also constitute important areas of coverage. The manuscript management system is completely online and includes a very quick and fair peer-review system, which is all easy to use. Visit $\mathrm{http}: / /$ www.dovepress.com/testimonials.php to read real quotes from published authors. 